\title{
Comparison of patients' and health care professionals' attitudes towards advance directives
}

Danielle Blondeau, Pierre Valois, Edward W Keyserlingk, Martin Hébert and Mireille Lavoie Universit Laval, Université du Québec à Trois-Rivières, McGill University, Guy and Gilbert, and Université Laval, Canada respectively

\begin{abstract}
Objectives-This study was designed to identify and compare the attitudes of patients and health care professionals towards advance directives. Advance directives promote recognition of the patient's autonomy, letting the individual exercise a certain measure of control over life-sustaining care and treatments in the eventuality of becoming incompetent.

Design-Attitudes to advance directives were evaluated using a 44-item self-reported questionnaire. It yields an overall score as well as five factor scores: autonomy, beneficence, justice, external norms, and the affective dimension.

Setting-Health care institutions in the province of Québec, Canada.
\end{abstract}

Survey sample-The sampling consisted of 921 subjects: 123 patients, 167 physicians, 340 nurses and 291 administrators of health care institutions. Results-Although the general attitude of each population was favourable to the expression of autonomy, multivariate analysis of variance (MANOVA) indicated that physicians attached less importance to this subscale than did other populations $(p<.001)$. Above all, they favoured legal external norms and beneficence. Physicians and administrators also attached less importance to the affective dimension than did patients and nurses. Specifically, physicians' attitudes towards advance directives were shown to be less positive than patients' attitudes.

Conclusion-More attention should be given to the importance of adequately informing patients about advance directives because they may not represent an adequate means for patients to assert their autonomy. (Fournal of Medical Ethics 1998;24:328-335)

Keywords: Advance directives; durable power of attorney; living will; professionals' attitudes; bioethics

\section{Introduction}

Advance directives are becoming an increasingly common social phenomenon; they are also becoming a topic that appears in the literature a regular basis. Directives give individuals (an opportunity to exercise a certain measure of chtrol over care and treatment, especially lifesustaining treatments. Directives are drawn up in advance by a person capable at that point of majing decisions. Specifically, advance directiges express the wishes of the individual to be applifed at a time when he or she has become incapable of making decisions. ${ }^{1}$ Over the past few years, this acknowledgment of patients' right to S\&effdetermination has raised awareness of Re importance of informed consent, as well as ân the emergence of instruments such as advarge directives.

The two most common types of directives a्re living wills and durable powers of attorney. Livi wills generally consist of a document in whicha lucid person expresses his or her refusal to hअ life artificially sustained in the event of a terminal illness. This document may also include $\overline{\bar{\sigma}}$ a person's preferences regarding the use of lifesustaining treatments". ${ }^{2}$ Durable powers of attorney designate a mandatary or proxy who can malke therapeutic decisions for the patient should he ${ }^{3}$ or she become unable to make such decisions. In current practice in both the United States Canada, there is a trend to set up these directies and to promote their use. The origin of directifs can be traced back to 1976, when the Natuical Death Act was passed in California, giving living wills official legal status. To date, most Amerigegn states have passed legislation that provides a legal framework for living wills, durable powers attorney, or both at the same time. ${ }^{34}$ In Cana\&a, however, there is as yet no explicit legislation gowerning living wills, although at the time this pafer was written the province of Ontario had proposed four bills $(74,108,109,110)$ designed to lega电e advance directives. Durable powers of attorey hold legal status in the provinces of Québec and Nova Scotia. The passage of legislation governing 
advance directives does promote their use, which is becoming more and more widespread. ${ }^{5}$

Keyserlingk uses the term "second generation" in describing the evolution and scope of this phenomenon. $^{6}$ The quantity of literature on advance directives serves as a broad reflection of the interest and enthusiasm they arouse among researchers. However, nearly everything that has been written on the topic involves theoretical analyses of a philosophical and legal nature, with only a small percentage of articles reporting empirical research findings. Of the 700 articles on the subject published up to 1993 , only $31(4 \%)$ reported empirical findings. Since 1993, that figure has risen to $7.8 \%$, and has remained stable. Research generally takes the form of surveys, which essentially provide descriptions of the phenomenon. Among the topics addressed, for example, are frequency of use and type of directives chosen, attitudes towards these documents, understanding of these documents, patients' capacity when signing directives, the influence of or need for education programmes, consistency of choices made by patients with those made by their family or physician, and so on. Although this research is of undeniable interest, there are few studies that enable us to gain a better understanding of the nature, usefulness, value and efficacy of advance directives..$^{7-9}$ In addition, although a slight increase in the volume of empirical research has been observed, ${ }^{10}$ as far as we know none of the research is based on a defined theoretical framework that would provide a foundation for understanding this phenomenon.

Within this context, an empirical research project based on a theoretical framework was initiated, with the overall objective of exploring and comparing the attitudes of health care professionals and patients towards advance directives. This research concerns only the province of Québec in Canada and any comparison with others countries could be hazardous.

\section{Theoretical framework}

The theoretical framework for this research project was not drawn solely from the field of bioethics. In fact, the epistemological status of this science is not clearly defined, and bioethics offers no theoretical models that can easily be put into operation. For that reason, frame of reference is inspired not only by philosophical principles but also by psychosocial theories. Indeed, applied ethics proposes philosophical references through norms and principles which facilitate the understanding of attitudes formed, amongst other things, from beliefs, values and principles. Also, applied ethics, as opposed to clinical ethics, is more congruent with psychosocial theories of attitudes. ${ }^{11}{ }^{12}$ In fact, these theories favour the putting into operation of constructs derived from the principles approach. Beauchamp and Childress $^{13}$ propose four principles (autonomy, beneficence, non-maleficence, and justice) instead of only one as suggested by monist theories. ${ }^{14-17}$ In short, the theoretical framework selected arises from an attempt to establish attitudinal models in the health care field in general, and specifically in this case, in bioethics.

This model is designed to highlight the nature of beliefs that give rise to attitudes. Behaviours, which are not the subject of this article, result from attitudes. In the case of patients, the behaviour of interest in this study consists in providing or not providing advance directives; in the case of health care professionals, it involves respecting or failing to respect those directives.

Beliefs were divided into two categories: ethical beliefs, divided into three subscales, and other beliefs, divided into two subscales. The first broad category of beliefs explicitly includes the following dimensions: (a) beliefs reflecting autonomy, (b) beliefs reflecting beneficence/non-maleficence, and (c) beliefs reflecting justice. These dimensions are in accordance with the studies of several authors. ${ }^{131718}$ Autonomy is the ability to govern oneself, make decisions and exercise freedom of choice. For example, a patient may provide a directive that expresses his or her wishes regarding life-sustaining treatments. Similarly, a health care professional may decide to respect a directive, thereby recognizing the patient's autonomy. Beneficence is defined as the moral obligation to do good to another person and to act in his or her best interest, while non-maleficence involves the concept of "doing no harm". Specifically, the attitude that results from this type of belief may lead to failure to respect advance directives. A therapeutic decision may be based exclusively on objective clinical assessments, out of concern for beneficence, thereby contravening the wishes expressed in an advance directive and overruling the patient's autonomy. On the other hand, respecting a directive may be motivated by the idea of doing no further harm to the patient, out of concern for non-maleficence rather than consideration of expressed wishes. Justice is used in the general sense of acknowledging the equality of human beings by eliminating sources of discrimination such as age, prognosis, and current ability to consent. In other words, whether to respect a directive should not, for example, depend on the age of the signatory. Whatever characteristics apply to those involved, whether they are con- 


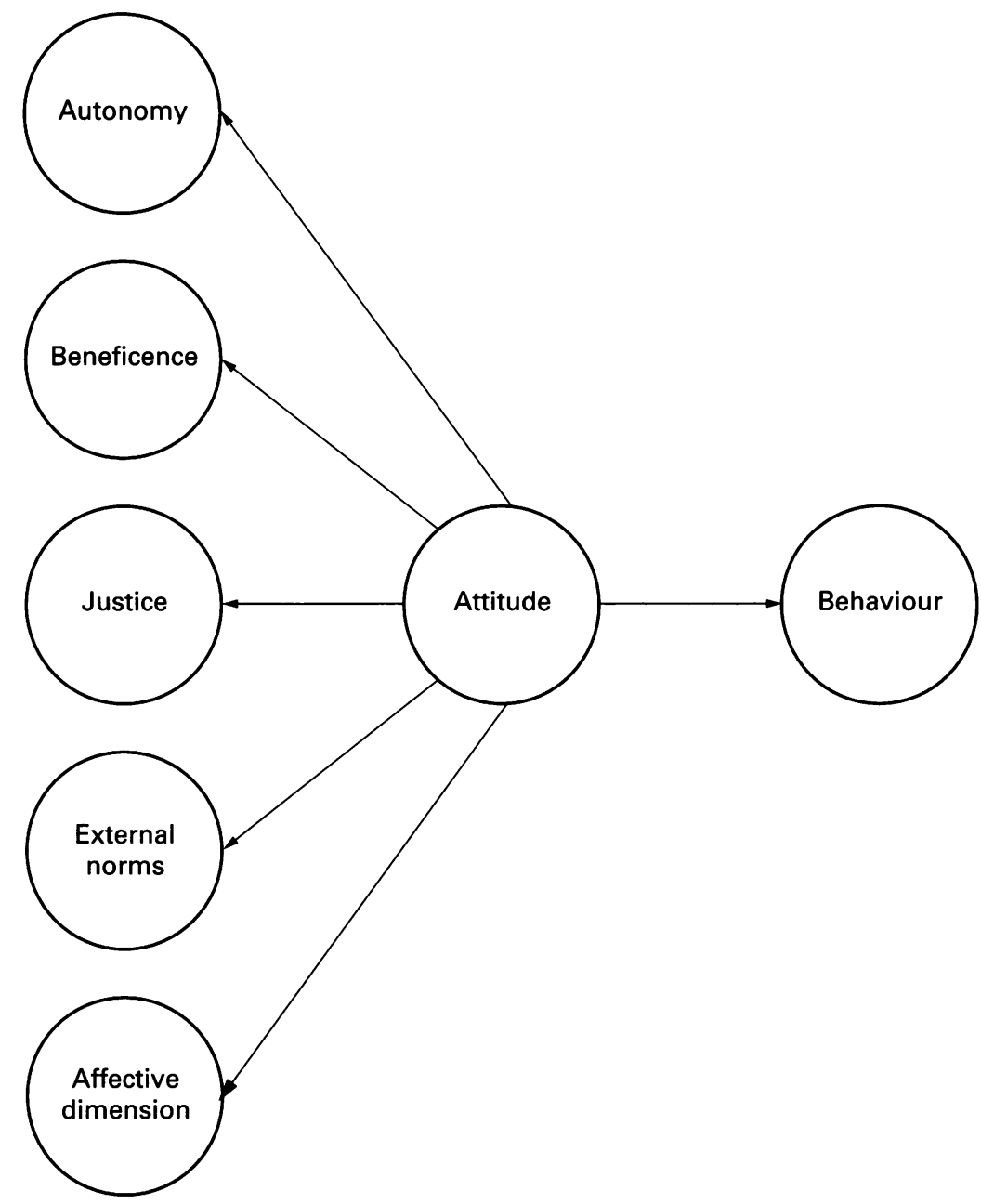

Figure 1 Theoretical framework

fused, young or old, everyone is entitled to the same consideration.

Other beliefs, apart from ethics, are classified under the following subscales: (a) beliefs regarding advantages and disadvantages associated with the external norms dimension and (b) beliefs regarding advantages and disadvantages associated with the relationships/affective dimension. External norms refer to standard aspects related to the validity of documents such as living wills and durable powers of attorney. This includes opinions from associations that may eventually recommend that directives be respected or not respected; legal considerations (legal status, lapse of time between signature and application, uncertain interpretation, etc), which may motivate failure to respect directives, and administrative policies that may, due to economic rationalization for example, promote the use of advance directives. The relationships/affective dimension involves relationships between the patient, the caregiving team and the family. For example a physician may refuse to comply with the wishes expressed in an advance directive if the family has objections. Affective reasons also include fears, convictions and feelings that arise from the approach of death. For example, fear of suffering may lead a patient to sign an advance directive indicating a desire for rapid relief of pain.

In summary, the model suggests that nan individual is likely to have a positive attituefle towards advance directives if he or she belieses that the directives promote the expressiono of wishes (autonomy) and equity among hunfan beings (justice), and that they contribute, er example, to helping the family cope with the empotional burden or reduce the fear associated with the risks of relentless therapeutic efforts (relationships/affective dimension). An individal is likely to have a negative attitude towasds advance directives if he or she believes that (a) pursuing the best clinical interests of the patient 
(beneficence) and (b) considerations of an administrative and legal nature (external norms) should prevail over written wishes.

In the absence of factual data regarding the use of advance directives in Québec, we felt it important to explore the underlying attitudes that determine whether or not advance directives are made. First of all, it was crucial to identify the attitudes of four groups of individuals (physicians, nurses, health care administrators and patients) towards advance directives. Secondly, we wanted to compare the respective attitudes of these populations. Based on the literature and the theoretical context, patients' attitudes towards advance directives are likely to be as positive as the attitudes of health care professionals (physicians, nurses and administrators). However, the reasons or beliefs that determine attitudes may vary from group to group. The objective of this study was therefore to verify differences between health care professionals and patients based on five subscales that together comprise attitude towards advance directives: autonomy, beneficence/non-maleficence, justice, external norms, and relationships/affective dimension.

\section{Method}

\section{SUBJECTS}

The sampling of 921 subjects was composed of patients, physicians, nurses and administrators (nursing directors, directors of professional services, and executive directors). The patients ( $\mathrm{n}=$ 123; 42 men and 81 women) were selected from amongst volunteers who came forward at regional general meetings and the annual general meeting of patients' committees affiliated with the Québec Provincial Patients' Committee. The physicians were recruited through the Professional Corporation of Physicians of Québec from a stratified sampling based on sphere of activities (general practitioners and specialists) and specialties likely to be exposed to the phenomenon of advance directives. Out of a total of 690 physicians, 167 (24.2\%; 117 men and 50 women) participated in the research project. The nurses were selected through the Québec Order of Nurses from a stratified sampling based on practice setting (for example, seniors' residences and chronic-care facilities) and unit (for example, oncology, cardiology). Of the 700 nurses who were approached, $340(48.7 \% ; 28$ men and 312 women) agreed to participate. Hospital administrators throughout the province (625) were contacted through the Québec Order of Nurses and the Québec Hospital Association. The response rate was $46.7 \%(n=$ 291; 141 men and 150 women). The relative degree of precision for the physician, nurse, and administrator samples was $3 \%$ with a confidence level of $95 \%$. The average ages of patients, physicians, nurses and administrators were $64.7,47.7$, 39.7 and 47.9 respectively.

\section{QUESTIONNAIRE}

A questionnaire was drawn up to elicit subjects' attitudes towards advance directives. The questionnaire included explanatory notes about various advance directive forms, as well as sample living wills and durable powers of attorney. The living will is a form on which a person can indicate what care (treatment) he would accept or refuse should he become very ill or, for example, unconscious. In the living will, people therefore state, while still competent and in possession of their faculties, how they would wish to be treated should they become too ill to express their wish. The living will is a declaration made and signed by the person concerned. It concerns the treatment and care desired or refused. It provides for a situation where the person would be incapable of expressing his or her wishes. The durable power of attorney designates a person called in Québec a mandatary, who is thereby authorised to make decisions about care and treatment when the patient can no longer do so. Decisions are made solely in the patient's interest and, if possible, take into account the wishes expressed by the patient.

Another section of the questionnaire, containing 44 questions, was designed to measure five subscales that together comprise the attitude of subjects. The items were taken from a preliminary qualitative study of 43 patients, 12 health care administrators, 25 nurses and ten physicians. More specifically, open-ended questions were used to elicit respondents' perceptions of the advantages and disadvantages associated with the use of advance directives. Following a content analysis and as suggested by Ajzen and Fishbein, ${ }^{12}$ the most frequently given responses were retained for the questionnaire.

Of the 44 items retained, seven involved autonomy, seven beneficence/non-maleficence, seven justice, 13 external norms, and ten relationship/affective dimensions. For example, the statement: "By signing a form, a person can spare his or her nearest and dearest many concerns" came under the subscale of relationships/affective dimension. The statement: "No matter what the illness, the wishes expressed in a form should be respected" came under the subscale of justice. The subjects were asked to show on a Likert-type six-point scale their level of agreement $(+6)$ or disagreement $(+1)$ with each of 44 statements. The questionnaire was tested for accuracy on 105 subjects. Results revealed that 
Table 1 Percentage and frequency (in parentheses) for health professionals and patients on descriptive questions

\begin{tabular}{|c|c|c|c|c|c|c|}
\hline \multirow[b]{2}{*}{ Variables } & \multicolumn{4}{|c|}{ Health professionals } & \multirow[b]{2}{*}{$\begin{array}{l}\text { Patients } \\
(n=123)\end{array}$} & $\overline{\bar{\varnothing}}$ \\
\hline & $\begin{array}{l}\text { Physicians } \\
(n=167)\end{array}$ & $\begin{array}{l}\text { Nurses } \\
(n=340)\end{array}$ & $\begin{array}{l}\text { Administrators } \\
(n=291)\end{array}$ & $\begin{array}{l}\text { Total } \\
(n=798)\end{array}$ & & $\overrightarrow{\overrightarrow{\vec{P}}}$ \\
\hline \multicolumn{6}{|c|}{ Awareness of existence of documents: } & \\
\hline - Yes & $92.8(155)$ & $94.4(321)$ & $95.9(279)$ & $94.6(755)$ & $54.5(67)$ & $\overline{\bar{s}}$ \\
\hline$\bullet$ No & $7.2(12)$ & $5.6(19)$ & $4.1(12)$ & $5.4(43)$ & $45.5(56)$ & \\
\hline \multicolumn{7}{|l|}{ Belief in legal status of: } \\
\hline Durable power of attorney & & & & & & \\
\hline - Yes & $73.1(122)$ & $81.2(276)$ & $88.3(257)$ & $82.1(655)$ & $75.6(93)$ & \\
\hline$\bullet$ No & $26.9(45)$ & $18.8(64)$ & $11.7(34)$ & $17.9(143)$ & $24.4(30)$ & \\
\hline \multicolumn{6}{|l|}{ Living will } & \\
\hline - Yes & $53.3(89)$ & $73.5(250)$ & $48.8(142)$ & $60.3(481)$ & $68.3(84)$ & \\
\hline$\bullet$ No & $46.7(78)$ & $26.5(90)$ & $51.2(149)$ & 39.7 (317) & $31.7(39)$ & \\
\hline \multicolumn{6}{|l|}{ Clinical experience: } & \\
\hline - Yes & $46.7(78)$ & $34.4(117)$ & - & - & - & \\
\hline$\bullet$ No & $53.3(89)$ & $65.6(223)$ & - & - & - & ĩ \\
\hline \multicolumn{6}{|l|}{ Type of document signed: } & \\
\hline Durable power of attorney & $6.6(11)$ & $8.5(29)$ & $17.5(51)$ & $11.4(91)$ & $22.0(27)$ & \\
\hline - Living will & $10.8(18)$ & $4.1(14)$ & $5.2(15)$ & $5.9(47)$ & $11.4(14)$ & \\
\hline - No document & $76.0(127)$ & $76.5(265)$ & $71.5(208)$ & $74.6(595)$ & $46.3(57)$ & \\
\hline - Other & $0.0(0)$ & $2.9(10)$ & $3.4(10)$ & $2.5(20)$ & $10.6(13)$ & \\
\hline - Non response & $6.6(11)$ & $8.0(27)$ & $2.4(7)$ & $5.6(45)$ & $9.7(12)$ & \\
\hline
\end{tabular}

the questionnaire has clear psychometric qualities (test-retest reliability $=0.89$; internal consistency $=0.90$ ). The third section of the questionnaire explored awareness of the existence of advance directives, types of documents signed, designation of mandataries, and clinical experience.

\section{DATA COLLECTION}

Questionnaires for patients were distributed by volunteers at various meetings with the provincial patients' committee. Those requiring assistance (for example, the blind, paraplegics, etc) were offered support by research professionals or members of the committee. Most of the questionnaires were collected on site, with a few returned by mail. Questionnaires were mailed out to physicians, nurses and administrators. A reminder letter was automatically sent out five days later. Confidentiality was guaranteed in all cases.

\section{Results}

The results of this study will be presented in two sections: first of all, the descriptive data; secondly, a test of the research hypothesis.

\section{DESCRIPTIVE DATA \\ Awareness of the existence and status of advance directives}

As shown in table 1, results indicated that most of the health care professionals $(94.6 \%)$ stated that they were aware of the existence of advance directives. Amongst patients, awareness of directives was significantly lower at $54.5 \%, \chi^{2}(1)=173.3$, $(\mathrm{p}<0.0001)$. Both professionals and patients strongly believed $(82.1 \%$ and $75.6 \%)$ that the durable power of attorney, called a "mandate" in
Québec, is a legal document, which is in fact the case. ${ }^{19}$ Most of the respondents also thought that the living will was a legal document, although in Québec it is not in fact expressly recognizgdoas such by law. This belief is stronger amongst norses $(73.5 \%)$ and patients $(68.3 \%)$ than amongs physicians $(53.3 \%)$ and health care administ $(48.8 \%)$.

\section{Clinical experience}

According to our findings, $46.7 \%$ of the phe cians and $34.4 \%$ of the nurses have previously treated patients who have signed directives. HWever, the frequency of exposure to advance directives since their introduction (in 1986 for liv wills and 1990 for durable powers of attorney is relatively low, at five exposures for durable powers of attorney and 6.7 exposures for living wâlls amongst physicians; 4.1 exposures for durable powers of attorney and 3.6 exposures for living wills among nurses.

Types of advance directives provided by respondeñ Table 1 shows that $74.6 \%$ of professionals and $46.3 \%$ of patients have not provided advance diresctives. However, durable powers of attorney gdo appear to be the most popular category amongst those documents that have been provided. NE्gne the less, only $11.4 \%$ of professionals and $22 \%$ of patients have in fact provided such documents.

\section{Designation of mandatary}

In $62.2 \%$ of cases, health care professionals designated their spouse as their mandatary; a smaler proportion $(10.5 \%)$ designated a child. The figures are reversed when we look at patients, with 

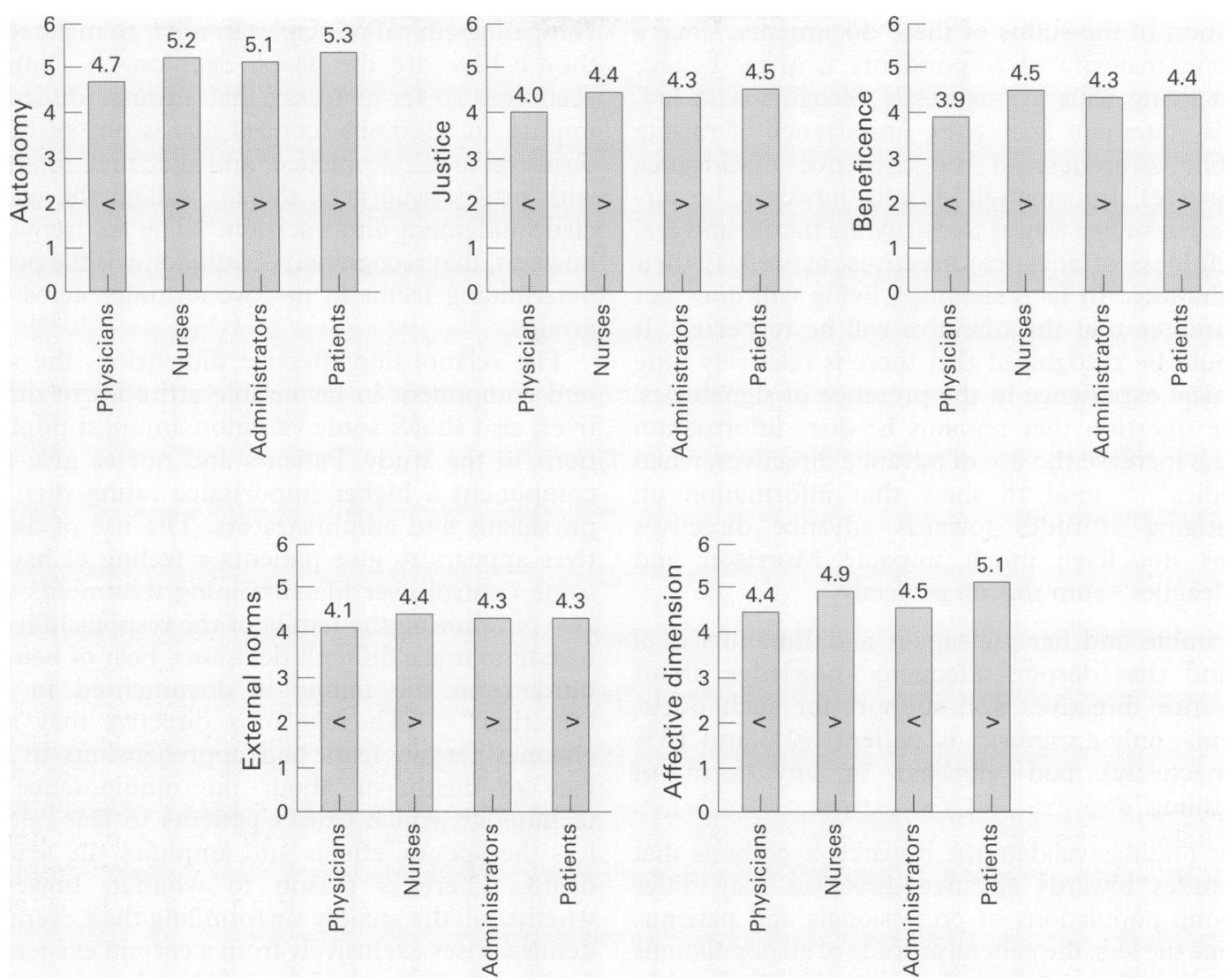

Figure 2 Significance differences between populations for each subscales (items from the beneficence and external norms subscales were reversed).

a higher proportion (55.6\%) designating one of their children rather than their spouse $(14.8 \%)$.

Some respondents have themselves been designated as mandataries. Amongst health care professionals, $22.4 \%$ are mandataries, designated by their parents $(63.1 \%)$ or by their spouse $(19.6 \%)$. The same scenario is seen amongst patients, with $17 \%$ having been designated as mandataries, by their parents $(42.9 \%)$ or spouses $(28.6 \%)$ respectively. In virtually all cases $(88 \%)$, mandatary and designator did discuss their wishes regarding life-sustaining treatment.

\section{TESTING THE RESEARCH HYPOTHESIS}

Although the subjects did, overall, have an extremely positive attitude towards advance directives (average $=5.2$ on a 6 -point scale), inferential results show differences of attitudes amongst the various populations. Inasmuch as recent studies showed that parametric tests seem perfectly adequate when a 6-point Likert scale is used, ${ }^{2}$ and that the $F$ test is insensitive to violations of the assumption of normal distributions, ${ }^{21}$ we judged it appropriate to analyse our data with parametric tests such as multivariate analysis of variance
(MANOVA). The Hotelling test revealed that there were differences in the subscales of attitude towards advance directives (taken globally) between physicians, nurses, administrators and patients, $F(15,2735)=10.75$, $(p<0.0001)$. Univariate analyses of variance (ANOVAs) were then applied on each subscale. The results shown in figure 2 indicated that each population was favourable to patient autonomy and the principle of justice, although physicians attached less importance to these dimensions than other populations $(p<0.05)$. Secondly, physicians and administrators appear to favour beneficence more than nurses and patients $(p<0.05)$. Thirdly, physicians and administrators attached less importance to the affective dimension than did nurses and patients. Finally, physicians favoured legal external norms more than nurses and administrators.

\section{Discussion}

The descriptive findings suggest that health care professionals are more aware of the existence of advance directives than are patients. However, some confusion clearly remains regarding the per- 
ception of the status of these documents, since a strong majority of respondents wrongly believe that living wills are expressly recognized in law. This statement shows the importance of raising public awareness of the existence of advance directives. Information should, however, be targeted in such a way as to clarify the nature and real usefulness of advance directives, as well as their limitations. In fact, signing a living will does not guarantee that the directive will be respected. It should be recognized that there is relatively little clinical experience in the presence of signatories. The question that remains is: does information alone increase the use of advance directives, when studies $^{22}{ }^{23}$ tend to show that information on changing attitudes towards advance directives does not have much impact? Morrison and colleagues $^{22}$ sum this up perfectly:

"Gamble and her colleagues and Emanuel et al found that despite adequate knowledge about advance directives and support for such documents, only a minority of patients $(0 \%$ and $18 \%$ respectively) had engaged in any form of planning". ${ }^{24}$

Our findings validate the research hypothesis that attitudes towards advance directives may differ among populations of professionals and patients. None the less, the general attitude of all populations is favourable to advance directives. This finding has emerged from previous studies of physicians, ${ }^{25-28}$ nurses $^{29}$ and patients. ${ }^{30-32}$ However, our research does constitute an advance in the understanding of attitudes behind behaviours related to providing and respecting advance directives. It identifies five subscales that determine attitude: autonomy, beneficence/non-maleficence, justice, external norms and relationships/affective dimension.

In the latter category, for example, fear of suffering, the desire to avoid being a burden on the family or to avoid conflicts between the family members are sufficient reasons to sign a directive. The results suggest that relationships between family, physician and patient must be harmonious if the wishes of the signatory are to be respected.

There are also variations among the target populations in terms of the components of positive attitudes. Although autonomy is the determining variable across all groups, physicians do have the lowest score on this subscale. It therefore seems fair to suggest that recognition of autonomy may conflict with physicians' desire for beneficence and applying their professional judgment. This finding is also in line with those of previous studies. ${ }^{29-34}$ For example, Danis and colleagues concluded: "Thus, the data suggest that in caring for incapacitated patients, physicians balance respect for autonomy with other competing ethical principles in order to make what they believe are the wisest decisions". ${ }^{35}$ Zinb产g even goes so far as to say that advance directifes impose an additional control that is not useful In $_{\text {in }}$ terms of medical practice, and that they interfegre with professional acts, thereby calling the phsician's judgment into question. ${ }^{28}$ The fact remain however, that recognition of autonomy is the prime determining factor in positive attitudes across all groups.

The relationship/affective dimension, the se्cond component in favourable attitudes to directtives, also shows some variation amongst popupations in the study. Patients and nurses give this component a higher importance rating than ido physicians and administrators. The use of direftives appears to give patients a feeling of having some control over life-sustaining treatments amd also of relieving the family of the responsibilitysof having to make difficult decisions. Fear of being a burden on the family is documented in literature. $^{36}{ }^{37}$ The use of a directive may a\$so channel certain fears and apprehensions in the face of death, or about the omnipotence $ठ f f$ technology, which causes patients to fear rejestless therapeutic efforts and amplifies the feariof death. There is reason to wonder, how whether all the anxiety surrounding their event demise arises exclusively from a certain existengial fear or also from a real fear of abandonnementक्के health care professionals.

It comes as no surprise to see that nurses arejas favourable to the relationship/affective dimension as their patients. In fact, since they play an exple trit role in protecting and defending the interests of patients (ie advocacy), there is reason to believe that they espouse the motivations of their clienteife.

Finally, physicians and administrators consiğger the relationship/affective dimension as less important than do groups of patients and nurses. In addition, the family's objections to the patient's request $^{38}$ and consensus between physician family are important criteria in determin 포ำ whether advance directives are recognized. ${ }^{28}$ O

In summary, despite variations across popungations in the study, attitudes towards advange directives are positive, and are essentially basedorn the recognition and promotion of autonomy, beneficence/non-maleficence, justice, exter al norms and relationship/affective considerations. Our findings illustrate the importance of the five subscales that together form attitudes towasds advance directives. However, the value $\$$ relevance of these presently available instruments, especially in promoting autonomy, would seento warrant closer examination. In other words, are advance directives an efficient and useful tech- 
nique in the recognition of autonomy? If not, what techniques would enable us better to achieve that goal in real terms?

Future studies will need to explore the connections between attitudes and behaviours that play a real role in promoting autonomy. Secondly, future studies should seek to establish other techniques in addition to advance directives that would encourage patients to express their wishes regarding decisions to be made when death draws near, and would encourage professionals to respect those wishes.

\section{Acknowledgement}

This research was funded by grants from the Social Sciences and Humanities Research Council of Canada and the Fonds pour la formation de Chercheurs et l'Aide à la recherche. We gratefully acknowledge the data collection and data management efforts of Mireille Lavoie and Michèle Lanquin-Éthier. Correspondence concerning this article should be adressed to Danielle Blondeau, Faculty of Nursing, Université Laval, Pavillon Comtois, Québec, Canada, G1K 7P4. Electronic mail may be sent to Danielle.Blondeau@fsi. ulaval.ca

Danielle Blondeau, PhD, is Professor Titulaire in the Faculty of Nursing at Université Laval, Quebec, Canada. Pierre Valois, PhD, is Associate Professor in the Department of Education Sciences at the Université du Québec à Trois-Rivières, Canada. Edward W Keyserlingk, PhD, is Associate Professor in the Faculty of Medicine, McGill University, Canada. Martin Hébert, $M A$, is a Lawyer at the law firm of Guy and Gilbert, Montreal, Canada, and Mireille Lavoie, MSc, is a Professional Researcher in the Faculty of Nursing, Université Laval, Canada.

\section{References and notes}

1 Downie J. Where there is a will, there may be a better way: legislating advance directives. Health Law in Canada 1992;12:7389.

2 Advance Directives Seminar Group, Centre for Bioethics, University of Toronto. Advance directives: are they an advance? Canadian Medical Association fournal 1992;146:127-34. (The quotation is from page 127.)

3 Annas GJ. The health care proxy and the living will. New England fournal of Medicine 1991;324:1210-3.

4 Cranford RE. Advance directives: The United States experience. Humane Medicine 1993; 9:64-9.

5 A decision worth noting is that of the Ontario Court of Appeal in Malette v Shulman (1990). Georgette Malette was involved in an automobile collision. Suffering serious injury, she was brought to a hospital emergency room. In her purse, she had a Jehovah's Witness card, specifically refusing blood transfusion in any circumstances. She was unconscious and bleeding profusely. To save her life, Dr Shulman decided to do a blood transfusion, overriding Mrs Malette's advance directive. After she had recovered, she sued Dr Shulman. The court held that Dr Shulman was wrong to override Mrs Malette's directive and ordered him to pay $\$ 20,000$ for assault. This decision upholds the validity of a written advance directive and the obligation to respect the wishes expressed by the patient.
6 Keyserlingk EW. Second-generation advance directives: will reforming the law improve the practice? Humane Medicine 1993;9:57-63.

7 Emanuel EJ, Emanuel LL. Living wills: past, present, and future. Fournal of Clinical Ethics 1990;1:9-19.

8 Lynn J, Teno JM. After the Patient Self-Determination Act: the need for empirical research on formal advance directives. Hastings Center Report 1993;23:20-4.

9 Molloy DW, Harrison C, Farrugia MC, Cunje A. The Canadian experience with advance treatment directives. Humane Medicine 1993;9:70-6.

10 Dresser R. Confronting the "near irrelevance" of advance directives. Fournal of Clinical Ethics 1994;5:55-6.

11 Eagly AH, Chaiken S. The psychology of attitudes. New York: Harcourt Brace Jovanovich College Publishers, 1993.

12 Ajzen I, Fishbein, M. Understanding attitudes and predicting social behavior. Englewood Cliffs, NJ: Prentice Hall, 1980.

13 Beauchamp TL, Childress JL. Principles of biomedical ethics. New York: Oxford University Press, 1989.

14 Rawls JA. Theory of justice. Massachusetts: Harvard University Press, 1971.

15 Nozick R. Anarchie, état et utopie. Paris: Presses Universitaires de France, 1988.

16 Nozick R. The examined life. Philosophical meditations. New York: Simon \& Schuster, 1989.

17 Engelhardt HT. The foundations of bioethics. New York: Oxford University Press, 1986.

18 Veatch RMA. Theory of medical ethics. New York: Basic Books, 1981.

19 Public Curatorship Act and amendments to the Civil Code and other legislative provisions 1989: c 54

20 Rasmussen JL. Analysis of Likert-scale data: a reinterpretation of Gregoire and Driver. Psychological Bulletin 1989;105:167-70.

21 Sawilowsky S, Blair RC. A more realistic look at the robustness and type ii error properties of the $t$ test to departures from population normality. Psychological Bulletin 1992; 69: 79-99.

22 Morrison RS, Morrison EW, Glickman DF. Physician reluctance to discuss advance directives. Archives of Internal Medicine 1994;154:2311-8.

23 Holley JL, Nespor S, Rault R. The effects of providing chronic hemodialysis patients with written material on advance directives. American fournal of Kidney Diseases 1993;22: 413-8.

24 See reference: 22: 2311.

25 Davidson KW, Hackler C, Caradine D, McCord RS. Physicians' attitudes on advance directives. Fournal of the American Medical Association 1989;262:2415-9.

26 Hughes DL, Singer PA. Family physicians' attitudes toward advance directives. Canadian Medical Association fournal 1992; 146:1937-44

27 Brunetti LL, Carperos SD, Westlund RE. Physicians' attitudes toward living wills and cardiopulmonary resuscitation. fournal of General Internal Medicine 1991;6: 23-9.

28 Zinberg JM. Decisions for the dying: an empirical study of physicians' responses to advance directives. Vermont Law Review 1989;13:445-91.

29 Kelner M, Bourgeault IL, Hébert PC, Dunn EV. Advance directives: the views of health care professionnals. Canadian Medical Association fournal 1993;148:1331-8.

30 Broadwell AW, Boisaubin EV, Dunn JK, Engelhardt HT. Advance directives on hospital admission: a survey of patient attitudes. Southern Medical fournal 1993;86: 165-8.

31 Emanuel LL, Barry MJ, Stoeckle JD, Ettelson LM, Emanuel EJ. Advance directives for medical care - a case for greater use. New England fournal of Medicine 1991;324:889-95.

32 Mehran S, Singer PA. Canadian outpatients and advance directives: poor knowledge and little experience but positive attitudes. Canadian Medical Association fournal 1993;148: 1497-502.

33 Mower WR, Baraff LJ. Advance directives. Effect of type of directive on physicians' therapeutic decisions. Archives of Internal Medicine 1993;153: 75-81.

34 Danis M, Southerland L, Garrett JM, Smith JL, Hielema F et al. A prospective study of advance directives for life-sustaining care. New England fournal of Medicine 1991;324:882-8.

35 See reference: 34: 887.

36 Sugarman J, Weinberger M, Samsa G. Factors associated with veterans' decisions about living wills. Archives of Internal Medicine 1992;152:343-7.

37 Doukas DJ, Gorenflo DW. Analysing the values history: an evaluation of patient medical values and advance directives. fournal of Clinical Ethics 1993;4:41-5.

38 Hughes DL, Singer PA. Family physicians' attitudes toward advance directives. Canadian Medical Association fournal 1992; 146:1937-44 